\title{
Correction to: Crustal control on basement uplift beneath the Ghawar Anticline, Saudi Arabia-gravity modeling with receiver function constraints
}

\author{
Manoj Mukhopadhyay ${ }^{1} \cdot$ Saad Mogren $^{2} \cdot$ Basab Mukhopadhyay $^{3} \cdot$ Kasimahanti Durga Venkatesh $^{3} \cdot$ Eslam Elawadi $^{2}$ \\ Published online: 2 July 2020 \\ C Saudi Society for Geosciences 2020
}

Correction to: Arabian Journal of Geosciences (2020) 13:463 https://doi.org/10.1007/s12517-020-05433-4

The corresponding author did not notice the need to add "International Scientific Partnership Program-0039" in the Acknowledgement section. Given in this article is the corrected statement.

Acknowledgments One of us (M.M.) is thankful to the ViceRectorate for Graduate Studies and Research, International Scientific Partnership Program-0039, King Saud University, Riyadh, for support. Authors express their gratitude to Dr. N. Sundararajan, Chief Editor, AJGS and two anonymous reviewers for their comments on the review.

The online version of the original article can be found at https://oi.org/ $10.1007 / \mathrm{s} 12517-020-05433-4$

Basab Mukhopadhyay

basabmukhopadhyay@gmail.com;

basab.mukhopadhyay@gsi.gov.in

1 Department of Applied Physics, University of Technology,

Lae, Morobe Province 411, Papua New Guinea

2 King Saud University, P.O. Box 2455, Riyadh 11451, Saudi Arabia

3 Geological Survey of India, 29 J.L. Nehru Road, Kolkata 700016, India 